\title{
Effect of glutathione depletion on the cytotoxicity of xenobiotics and induction of single-strand DNA breaks by ionizing radiation in isolated hamster round spermatids
}

\author{
P. J. Den Boer, A. A. W. M. van Loon*, P. Mackenbach, \\ G. P. van der Schans $\dagger$ and J. A. Grootegoed
}

Department of Biochemistry II, Medical Faculty, Erasmus University Rotterdam, P.O. Box 1738, 3000 DR Rotterdam, The Netherlands; *Department of Radiation Genetics and Chemical Mutagenesis, Sylvius Laboratory, State University of Leiden, The Netherlands; and $\dagger T N O$ Medical Biological Laboratory, Rijswijk, The Netherlands

\begin{abstract}
Summary. The role of glutathione (GSH) in cellular protection mechanisms in round spermatids from hamsters was studied. Isolated spermatids were largely depleted of GSH by treating the cells for $2 \mathrm{~h}$ with the GSH conjugating agent diethyl maleate (DEM). This treatment resulted in a $90 \%$ decrease of the cellular GSH content, but did not affect the ATP content. Exposure of isolated spermatids to cumene hydroperoxide (CHP), a compound which is detoxicated by the GSH redox cycle, showed that the cytotoxicity of the peroxide was markedly potentiated by GSH depletion of the cells. The cytotoxicity was reflected by the cellular ATP content. A decrease of the ATP content of the GSH-depleted spermatids was observed at 5-6-fold lower CHP concentrations, as compared to control cells. An increased cytotoxicity in GSH-depleted cells was also observed using 1-chloro-2,4-dinitrobenzene (CDNB), which is a reactive compound that is detoxicated by glutathione conjugation. The induction of single-strand DNA breaks by gamma radiation was 3-5-fold higher in GSH-depleted spermatids as compared to control cells. This radiation-induced damage was estimated under hypoxic conditions (500 p.p.m. $\mathrm{O}_{2}$ in $\mathrm{N}_{2}$ ). GSH depletion did not affect the repair of single-strand DNA breaks following the irradiation. The present results indicate that cellular GSH has an important function in the defence mechanisms of round spermatids against peroxides, electrophilic xenobiotics and radiation-induced DNA damage.
\end{abstract}

Keywords: glutathione; spermatids; Sertoli cells; gamma-radiation; xenobiotics; hamster

\section{Introduction}

Glutathione (GSH) is a tripeptide containing a cysteine residue with a free sulphhydryl group, that is present in different mammalian cell types in a 0.5-10 mM concentration (Meister \& Anderson, 1983). Cellular GSH plays an important role in many biological processes including protection of cells. The sulphhydryl group of GSH is a strong nucleophile and confers cellular protection against damage produced by oxidants, electrophiles and free radicals (Meister \& Anderson, 1983). High concentrations of GSH are found in the testis of rats and mice (Calvin \& Turner, 1982; Grosshans \& Calvin, 1985). On the basis of protein content, the GSH level in adult rat testis is even similar to that in liver (Calvin \& Turner, 1982). Most of the testicular GSH is probably present in the developing germinal cells, which is in concordance with an increase of the testicular GSH concentration during the initiation of spermatogenesis (Calvin \& Turner, 1982; Grosshans \& Calvin, 1985). 
With respect to the protective effect of GSH, two mechanisms can be outlined. First, GSH is essential in a protective mechanism which involves inactivation of reactive oxygen species, including peroxides, formed in cellular oxygen metabolism. Peroxides are normally detoxicated through reduction by the enzyme glutathione peroxidase (EC 1.11.1.9), a reaction in which GSH is converted to oxidized glutathione (GSSG). This disulphide can be reduced by the enzyme glutathione reductase (EC 1.6.4.2) in the presence of NADPH, as illustrated in Fig. 1(a). The importance of this mechanism is indicated by a study from Starke \& Farber (1985), who observed that inhibition of glutathione reductase potentiated the killing of cultured hepatocytes by hydrogen peroxide. Another way to inactivate hydrogen peroxide involves catalase. In the present paper, we have focussed on glutathione-dependent defence mechanisms in spermatids, and we have not estimated catalase activities or the possible protective role of the enzyme in these cells. Second, many electrophilic xenobiotic compounds can be detoxicated through conjugation with GSH (Ketterer, 1986). The detoxication is initiated by the reaction of the electrophilic site of the foreign compound with the sulphhydryl group of GSH. This reaction is catalysed by a group of enzymes named glutathione S-transferases (GST; EC 2.5.1.18), as illustrated in Fig. 1(b). The formed conjugates are metabolized further to mercapturic acids, which can be released from the cells (Habig et al., 1974).

(a)

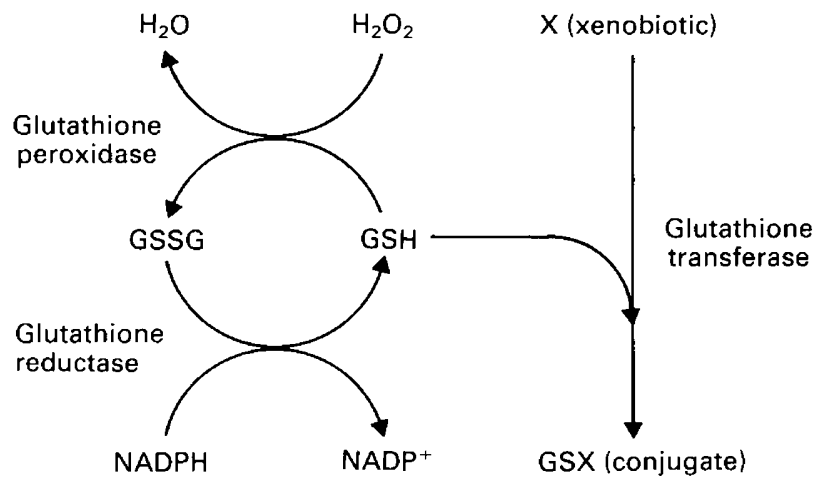

Fig. 1. The glutathione redox cycle (a) and the glutathione S-transferase reaction (b). GSH, reduced glutathione; GSSG, oxidized glutathione; GSX, conjugate between GSH and a xenobiotic.

The first mechanism is relevant in the context of the role of GSH in the protection of cells during irradiation. DNA is an important target for radiation damage in living cells (Greenstock \& Whitehouse, 1984). It has been shown that radiosensitivity of cells depends, among other parameters, on the intracellular thiol content. Depletion of GSH in Chinese hamster ovary cells in vitro by treatment with diethyl maleate (DEM), which is a GST substrate (Plummer et al., 1981), resulted in enhancement of the effect of X-rays on cell death (Bump et al., 1982), and in a sensitization of the induction of single-strand and double-strand breaks in DNA by gamma-irradiation (van der Schans et al., 1986). Human lymphoid cells depleted of GSH by treatment with buthionine sulphoximine (BSO), a specific inhibitor of GSH synthesis (Griffith \& Meister, 1979), also exhibited an increased radiosensitivity as compared to non-depleted controls (Dethmers \& Meister, 1981; Jensen \& Meister, 1983).

In the present paper, we studied whether the GSH-dependent protective mechanisms described above are active during spermatogenesis, in particular in round spermatids. Isolated round spermatids from hamsters were largely depleted of GSH using DEM, to study the effect of GSH depletion on the sensitivity of the cells to peroxides, cytotoxic effects of xenobiotics and ionizing radiation. 


\section{Materials and Methods}

Isolation and incubation of round spermatids from hamsters. Round spermatids from 32-34-day-old golden hamsters (Mesocricetus auratus) were isolated by velocity sedimentation at unit gravity, and further purified by Percoll-gradient centrifugation, using the same methods as described previously (Den Boer \& Grootegoed, 1988). The isolated cells were incubated in Dulbecco's phosphate-buffered saline, supplemented with 12 mM-sodium DL-lactate (PBS-L), or with lactate and 1.0 mM-glucose (PBS-GL). The PBS also contained antibiotics (Grootegoed et al., 1985) and $0.1 \%$ bovine serum albumin (BSA) (Fraction V; Sigma Chemical Company, St Louis, MO, USA). Approximately $0.3 \times 10^{6}$ cells were incubated in a volume of $0.25 \mathrm{ml}$ in polystyrene tubes (diameter $11.5 \mathrm{~mm}$ ), at $32^{\circ} \mathrm{C}$ in air.

Depletion of glutathione in isolated round spermatids. The GST substrate diethyl maleate (Aldrich Chemie, Bruxelles, Belgium) was used to deplete the GSH pool of the spermatids. It has been shown that this compound can be used to lower GSH levels of spermatids from rats effectively, without affecting the viability and ATP content of the cells (Den Boer et al., 1988). The isolated spermatids were partly depleted of GSH, by incubating approximately $50 \times 10^{6}$ cells for $2 \mathrm{~h}$ in the presence of $100 \mu \mathrm{M}$-diethyl maleate, in $25 \mathrm{ml}$ PBS-L (containing $0.1 \% \mathrm{BSA}$ ) at $32^{\circ} \mathrm{C}$. After the DEM treatment, the spermatids were washed twice with PBS-L or PBS-GL (centrifugation for 5 min at $200 \mathrm{~g}$ ) to remove the diethyl maleate. A stock solution of $310 \mathrm{~mm}$-diethyl maleate was prepared in pure ethanol, and diluted with PBS to the desired concentration. The final ethanol concentration in the incubation medium was $0.03 \%$ ( $/ \mathrm{v}$ ), and this concentration of ethanol was also added to the controls.

Irradiation of isolated round spermatids and detection of single-strand DNA breaks. Spermatids were irradiated using a ${ }^{60} \mathrm{Co}$-gamma-source (Gamma cell 100, Atomic Energy of Canada Ltd, Ottawa, Canada). Irradiations were performed at $0^{\circ} \mathrm{C}$, using $1 \mathrm{ml}$ of a cell suspension containing approximately $5 \times 10^{6}$ spermatids in PBS-L. The cells were irradiated under different gas atmospheric conditions. The desired oxygen concentration in the incubations was reached by leading a gas mixture of 500 p.p.m. $\mathrm{O}_{2}$ in $\mathrm{N}_{2}$ through the cell suspension, for 5 min before and during the irradiation. The oxygen content of the gas mixture leaving the system was measured as described by van der Schans et al. (1986). DNA damage in the spermatids was detected, after partial unwinding of the DNA by alkaline treatment, using a competitive immunoassay as described by van der Schans et al. (1989). The immunoassay is based on a monoclonal antibody directed against single-stranded DNA. Single-strand DNA breaks result in an increase of the amount of single-strand DNA after alkaline treatment. All samples were assayed in triplicate in the ELISA, and the detected DNA damage is expressed as the \% single-strandedness of the DNA (\% ss-DNA). The method is very sensitive and DNA damage can be determined using a low number of cells (van der Schans et al., 1989).

Estimation of the glutathione reductase activity. The glutathione reductase activity was estimated using the spectrophotometric method described by Carlberg \& Mannervik (1985). The assay mixture contained $0 \cdot 1 \mathrm{mM}-\mathrm{NADPH}$ (stock of $2 \mathrm{~mm}$ in $10 \mathrm{~mm}$ Tris-HCl, $\mathrm{pH} \mathrm{7.0)}$ ) and $1 \mathrm{~mm}$-oxidized glutathione (GSSG), in 0.2 mM-potassium phosphate buffer with $2 \mathrm{mM}$-EDTA ( $\mathrm{pH} 7 \cdot 0$ ). The enzyme preparation was prepared by lysing $5 \times 10^{6}$ spermatids in $500 \mu 1$ distilled water. After sonication ( 3 times for $5 \mathrm{sec}$, with a MSE 150 Watt Ultrasonic disintegrator, $20 \mathrm{kHz}$ at a setting of $7 \mu \mathrm{m})$, the homogenate was centrifuged $(5 \mathrm{~min}, 15000 \mathrm{~g})$ and $100 \mu \mathrm{l}$ of the supernatant were added to the assay (final volume $\mathrm{I} \mathrm{ml}$ ).

Fluorometric method for determination of reduced glutathione. Determination of GSH contents in spermatids was performed according to the method of Hissin \& Hilf (1976) and Grosshans \& Calvin (1985), but with some slight modifications as described by Den Boer et al. (1989).

Estimation of cellular ATP content. The cellular ATP content of the spermatids was estimated using the bioluminescent firefly luciferin-luciferase reaction (Lumit PM: Lumac, Meise, Belgium) as described by Grootegoed et al. (1984), with a model 6100 Pico-Lite Luminometer (Packard).

\section{Results}

\section{Glutathione depletion of isolated round spermatids by diethyl maleate}

To define the conditions for GSH depletion of hamster round spermatids, the GSH content of the isolated cells was estimated at different time-intervals during $2 \mathrm{~h}$ of incubation in the presence of $100 \mu \mathrm{M}$-diethyl maleate. Exposure of the cells to this glutathione S-transferase substrate resulted in a rapid loss of cellular GSH (Fig. 2). Within $5 \mathrm{~min}$ of exposure to diethyl maleate the GSH content was decreased already to $50 \%$ of the initial value, whereas the GSH content of spermatids incubated for $2 \mathrm{~h}$ in the absence of diethyl maleate remained high. The ATP content of the spermatids was not affected by diethyl maleate treatment (Fig. 2). A 2-h diethyl maleate treatment, carried out 
as described in 'Materials and Methods' and illustrated in Fig. 2, was applied in all further experiments, in order to study the effect of depletion of the cellular GSH pool on the sensitivity of the spermatids to various other treatments.

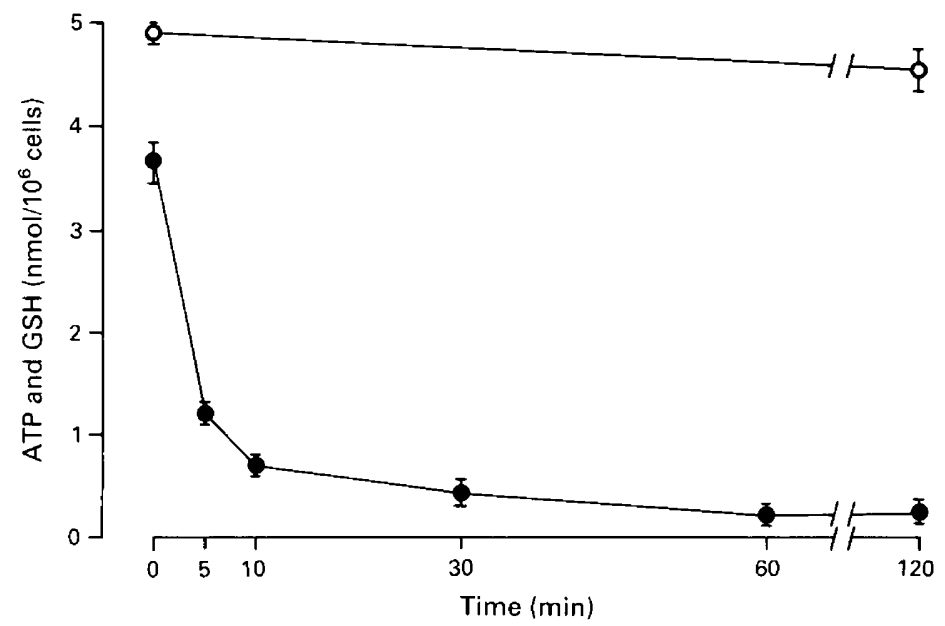

Fig. 2. Time-course of the effect of diethyl maleate on the cellular GSH and ATP contents of isolated spermatids. The GSH $\left(0_{--O}\right)$ and ATP $\left(O_{--O}\right)$ contents were estimated after different periods of incubation of the cells in the presence of $100 \mu \mathrm{M}$-DEM. The GSH and ATP contents after $2 \mathrm{~h}$ of incubation in the absence of DEM were $3.76 \pm 0.48$ and $4.45 \pm 0 \cdot 13 \mathrm{nmol} / 10^{6}$ cells, respectively. Values are the mean \pm s.d. of triplicate incubations.

\section{Effects of long-term incubation}

The ATP and GSH contents of control and GSH-depleted spermatids were estimated at different times during $96 \mathrm{~h}$ of incubation. The GSH content of the control cells decreased gradually during this period of incubation (Fig. 3). The GSH level of the GSH-depleted cells remained low after the DEM treatment, but this did not cause a rapid fall in the ATP content of these cells (Fig. 3). The ATP contents of both control and DEM-treated cells were unaffected up to an incubation period of $48 \mathrm{~h}$, but this was followed by a gradual decrease of the ATP contents. The decrease of the ATP level of the DEM-treated cells after $48 \mathrm{~h}$ followed the same pattern as that of the control cells (Fig. 3).

\section{Activity of glutathione reductase}

The presence of glutathione reductase is essential in the cellular defence against peroxides, as indicated in the 'Introduction'. The isolated spermatids contained a GSH reductase activity of $0 \cdot 93 \pm 0 \cdot 10 \mathrm{mU} / 10^{6}$ cells.

\section{Effect of low concentrations of 1-chloro-2,4-dinitrobenzene (CDNB) on the GSH content of spermatids}

The GSH and ATP contents of isolated spermatids were estimated after incubation for 1 and $18 \mathrm{~h}$ in the presence of low concentrations of CDNB, which is a much more reactive glutathione $\mathrm{S}$ transferase substrate than diethyl maleate. After $1 \mathrm{~h}$ of incubation in the presence of 1 or $5 \mu \mathrm{M}$ CDNB, the cellular GSH levels were lowered, and after $18 \mathrm{~h}$ in the presence of $5 \mu \mathrm{M}$-CDNB the 


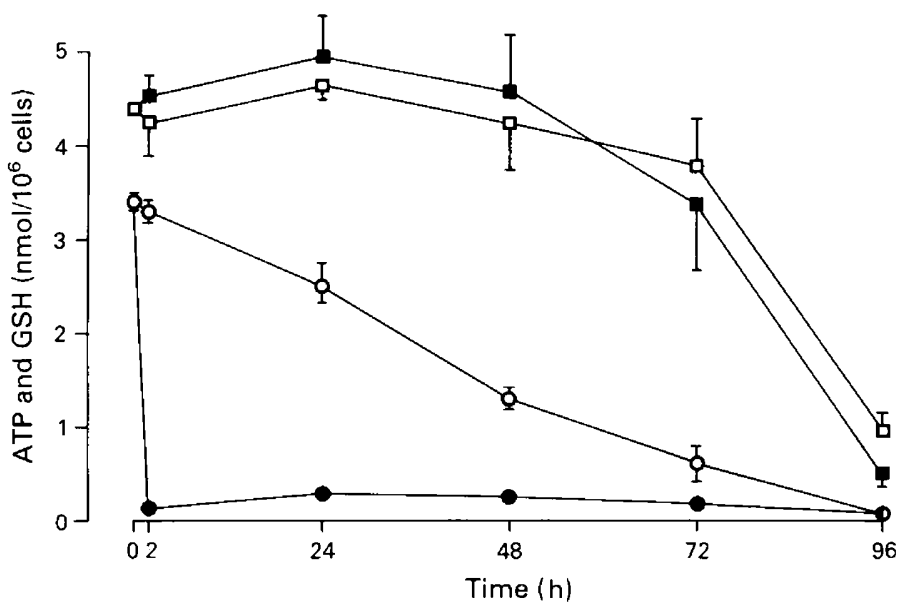

Fig. 3. Effect of long-term incubation of GSH-depleted and control spermatids on the cellular GSH and ATP contents. The spermatids were depleted of GSH during the first $2 \mathrm{~h}$ of incubation, as shown in Fig. 2 and described in 'Materials and Methods'. The GSH $(O, \mathbf{0})$ and $\operatorname{ATP}(\square, \boldsymbol{\square})$ contents of the spermatids were estimated after incubation of the cells for different time periods. The open symbols represent the control cells and the closed symbols the GSH-depleted cells. Values are the mean \pm s.d. of triplicate incubations.

GSH level was only $20 \%$ of controls (Table 1). It appears that low concentrations of CDNB can decrease the GSH content of the spermatids, but that this does not lead to an inhibition of ATP synthesis (Table 1). However, this may be true only when the cells are not exposed to higher concentrations of CDNB, or are not challenged otherwise to perform GSH-supported defence mechanisms. This was tested as described below.

Table 1. Effects of low concentrations of 1-chloro-2,4-dinitrobenzene (CDNB) on the ATP and GSH contents of isolated hamster spermatids

\begin{tabular}{lccc}
\hline $\begin{array}{l}\text { Incubation } \\
\text { period }(\mathrm{h})\end{array}$ & $\begin{array}{c}{[\mathrm{CDNB}]} \\
(\mu \mathrm{M})\end{array}$ & $\begin{array}{c}\text { ATP } \\
\left(\mathrm{nmol} / 10^{6} \text { cells }\right)\end{array}$ & $\begin{array}{c}\mathrm{GSH} \\
\left(\mathrm{nmol} / 10^{6} \text { cells }\right)\end{array}$ \\
\hline 0 & 0 & $4 \cdot 30 \pm 0 \cdot 30$ & $3 \cdot 65 \pm 0 \cdot 70$ \\
1 & 0 & $4 \cdot 01 \pm 0 \cdot 54$ & $3 \cdot 56 \pm 0 \cdot 09$ \\
1 & 1 & $4 \cdot 23 \pm 0 \cdot 32$ & $3 \cdot 03 \pm 0 \cdot 03$ \\
1 & 5 & $4 \cdot 86 \pm 0 \cdot 38$ & $2 \cdot 00 \pm 0 \cdot 10$ \\
18 & 0 & $4 \cdot 58 \pm 0 \cdot 09$ & $2 \cdot 62 \pm 0 \cdot 07$ \\
18 & 1 & $4 \cdot 74 \pm 0 \cdot 46$ & $2 \cdot 22 \pm 0 \cdot 05$ \\
18 & 5 & $4 \cdot 56 \pm 0 \cdot 21$ & $0 \cdot 61 \pm 0 \cdot 05$ \\
\hline
\end{tabular}

Round spermatids were treated for different periods with 1 or $5 \mu \mathrm{M}$-CDNB in PBS-GL. Values are the mean \pm s.d. of triplicate incubations.

\section{Potentiation of the cytotoxic effect of 1-chloro-2,4-dinitrobenzene (CDNB) and cumene hydroperoxide (CHP) after GSH depletion of spermatids}

Control and GSH-depleted spermatids were used to evaluate further the cytotoxicity of CDNB. In addition, the effect of the peroxide CHP was tested. The ATP content of GSH-depleted and control spermatids was estimated after $18 \mathrm{~h}$ of incubation in the absence or presence of different concentrations of CHP and CDNB. A complete loss of cellular ATP was observed after incubation of the GSH-depleted spermatids in the presence of low concentrations of CHP (Fig. 4a) or CDNB 
(Fig. 4b). The ATP content of the control spermatids was affected by these two compounds only at much higher concentrations (Figs $4 \mathrm{a} \& 4 \mathrm{~b}$ ). From these results, it can be concluded that the GSH-depleted cells are highly sensitive to both CHP and CDNB, as compared to control, non-GSH-depleted cells.

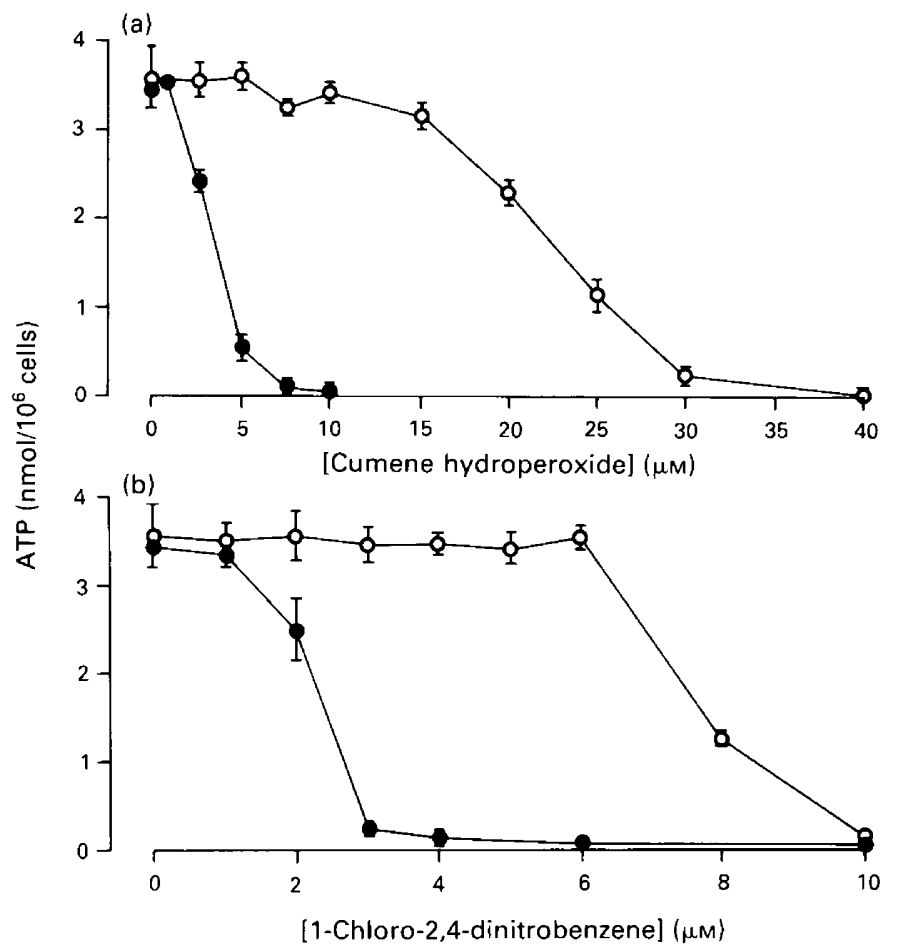

Fig. 4. Effect of GSH depletion of spermatids on the cytotoxicity of cumene hydroperoxide (CHP) and 1-chloro-2,4-dinitrobenzene (CDNB). The ATP contents of GSH-depleted (--) and control $\left(\mathrm{O}_{-} \mathrm{O}\right)$ spermatids were estimated after $18 \mathrm{~h}$ of incubation in the presence of different concentrations of CHP (a) or CDNB (b). The spermatids were depleted of GSH during the first $2 \mathrm{~h}$ of incubation, as shown in Fig. 2 and described in 'Materials and Methods'. The GSH content of the GSH-depleted spermatids was $0 \cdot 12 \pm 0.01 \mathrm{nmol} / 10^{6}$ cells, whereas the control cells contained $1.79 \pm 0.18 \mathrm{nmol} / 10^{6}$ cells. Values are the mean \pm s.d. of triplicate incubations.

\section{Effect of GSH depletion of spermatids on the induction and repair of single-strand DNA breaks}

The induction of single-strand DNA breaks ( $\%$ ss-DNA) was estimated in control and GSHdepleted spermatids, which were irradiated with a gamma dose of 2 or $5 \mathrm{~Gy}$. Irradiation resulted in a dose-dependent increase of the \% ss-DNA (Fig. 5a), both in control and in GSH-depleted spermatids. However, the radiation-induced DNA damage in GSH-depleted cells was $\sim 3$-fold higher than that in the control cells. The \% ss-DNA of non-irradiated control cells and non-irradiated GSH-depleted cells were not different (Fig. 5a).

The results described above were obtained by irradiation of the cells under a gas atmosphere of 500 p.p.m. $\mathrm{O}_{2}$ in $\mathrm{N}_{2}$. It has been reported that induction of radiation damage of cells is dependent on oxygen concentration, and that diminution of cellular GSH does not affect the induction of DNA damage by irradiation under aerobic conditions (van der Schans et al., 1986). In agreement with this no difference was observed in the \% ss-DNA in GSH-depleted and control cells after 


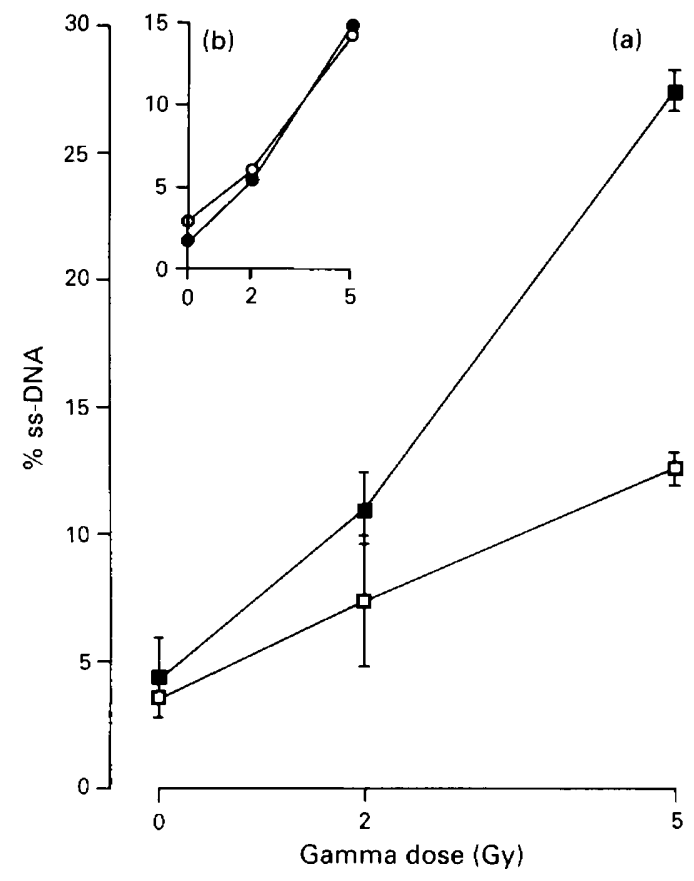

Fig. 5. Effect of GSH depletion of spermatids on the induction of single-strand DNA breaks by gamma radiation. GSH-depleted $(\mathbf{O}, \mathbf{\square})$ and control $(O, \square)$ spermatids were irradiated with different doses of gamma rays, using a controlled gas atmosphere of 500 p.p.m. $\mathrm{O}_{2}$ in nitrogen (a) or air (b). After partial unwinding of DNA, the \% single-strand DNA was measured as described in 'Materials and Methods'. Values are the mean \pm s.d. of quadruplicate determinations. The spermatids were depleted of GSH as described in 'Materials and Methods', which resulted in GSH contents of $0.14 \pm 0.02 \mathrm{nmol} / 10^{6}$ cells (a) and $0.26 \pm 0.01 \mathrm{nmol} / 10^{6}$ cells (b). The control cells contained $3.03 \pm 0.16 \mathrm{nmol} / 10^{6}$ cells (a) and $3.52 \pm 0.02 \mathrm{nmol} / 10^{6}$ cells (b). GSH contents are the mean \pm s.d. of triplicate incubations.

irradiation under air (Fig. 5b). In this experiment, air was led through the medium during the irradiation. Under standard incubation conditions, the gas atmosphere was air, but the air was not led through the medium. Consequently, the oxygen concentration surrounding the cells in all other experiments was most probably lower than the oxygen concentration in air. This is also indicated by the experiments on induction and repair of DNA damage described below.

In the experiments to study the repair of gamma-radiation induced single-strand DNA breaks, GSH-depleted and control cells were gamma-irradiated under standard incubation conditions. The induction of DNA damage in spermatids depleted of GSH was approximately 4-fold higher as compared to that in control cells (Fig. 6a). During a subsequent incubation at $32^{\circ} \mathrm{C}$, both the GSHdepleted and the control cells were able to repair most of the single-strand DNA breaks, induced by a gamma dose of $5 \mathrm{~Gy}$ (Fig. 6b). During the first $10 \mathrm{~min}$ of the repair period, a rapid decrease of the $\%$ ss-DNA was observed, and after $1 \mathrm{~h}$ of incubation the \% remaining ss-DNA was less than $20 \%$ of the initial damage. This result indicates that the round spermatids possess repair enzymes and that DNA repair in these cells is not dependent on a high cellular GSH content.

\section{Discussion}

The present experiments investigated whether isolated round spermatids from hamsters are protected against toxic effects of peroxides and xenobiotics, and also against gamma-radiation induced DNA damage, through GSH-dependent mechanisms. 

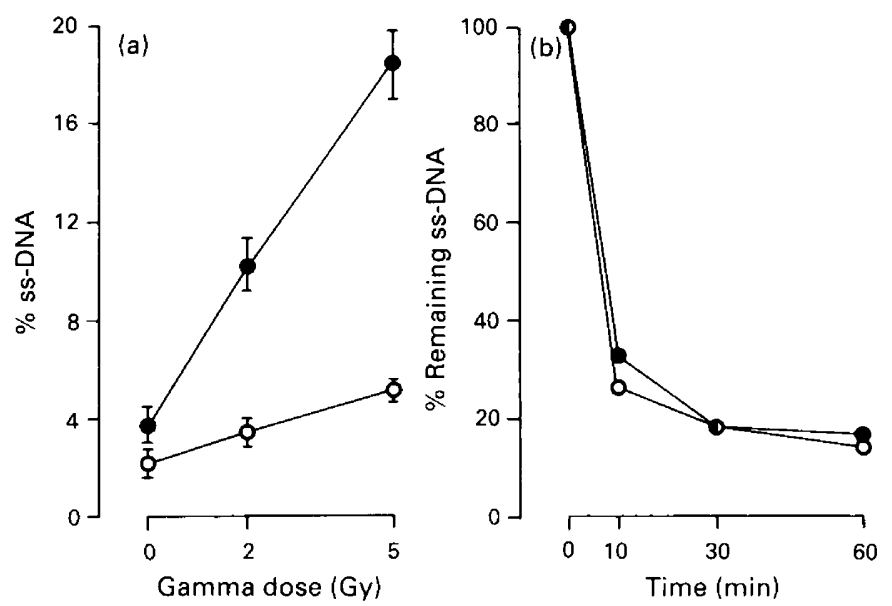

Fig. 6. Repair of single-strand DNA breaks in spermatids. GSH-depleted (- $)$ and control $(O--O)$ spermatids were irradiated under standard incubation conditions with different doses of gamma rays. The \% single-strand DNA was measured immediately following the irradiation (a), or at different time-intervals after treatment with a gamma-dose of $5 \mathrm{~Gy}$ (b). The spermatids were depleted of GSH as described in 'Materials and Methods', which resulted in a GSH content of $0.17 \pm 0.02 \mathrm{nmol} / 10^{6}$ cells $\left(2.98 \pm 0.12 \mathrm{nmol} / 10^{6}\right.$ cells in the control cells $)$. The ATP contents of the GSH-depleted and control spermatids were $3.89 \pm 0.44 \mathrm{nmol} / 10^{6}$ cells and $3.80 \pm 0.25 \mathrm{nmol} / 10^{6}$ cells, respectively. The values are the mean \pm s.d. of triplicate incubations. The \% ss-DNA was measured as described in 'Materials and Methods', and the values are the mean \pm s.d. of triplicate determinations (a) or the mean of duplicate determinations (b).

To obtain information on such a role of GSH in spermatids, the spermatids were largely depleted of GSH. The GSH content of the spermatids was decreased effectively by incubating the cells in the presence of low concentrations of the GSH conjugating agent (GST substrate) diethyl maleate. Low concentrations of diethyl maleate were used, since diethyl maleate can also cause lipid peroxidation. Rat hepatocytes exposed to $3 \mathrm{~mm}$-diethyl maleate showed a pronounced increase of lipid peroxidation (Miccadei et al., 1988), whereas lower concentrations of DEM resulted in depletion of the GSH content but did not cause lipid peroxidation and cell death (Högberg \& Kristoferson, 1977). Another, non-toxic method to deplete cells of GSH involves treatment of the cells with the GSH synthesis inhibitor BSO (Griffith \& Meister, 1979). This method, however, has little effect on spermatids, because isolated spermatids have a low capacity to synthesize GSH (Den Boer et al., 1989), and BSO was therefore not applied.

The observation that there was no effect of GSH depletion on the ATP content of the spermatids during long-term incubation indicates that there is no pronounced effect of GSH depletion on the viability of the isolated cells. This gave rise to the question to what extent GSH is involved in defence mechanisms in the isolated spermatids. Therefore, we studied whether GSH depletion of spermatids potentiated the cytotoxic effect of compounds, that are normally detoxicated through GSH-dependent mechanisms. To detect changes in the sensitivity of the spermatids to such compounds, cellular injury was assessed by estimating the ATP content of the spermatids. The ATP content may point to more subtle changes in cellular integrity, as compared to other parameters such as leakage of cytoplasmic enzymes and the uptake of trypan blue (Reed \& Fariss, 1984).

Cellular GSH depletion of the spermatids resulted in a low capacity of the cells to withstand oxidative stress generated by $\mathrm{CHP}$, as indicated by the cytotoxic effect of low CHP concentrations in DEM-treated cells. This is in agreement with observations in tumour cells, showing that GSH depletion of mastocytoma and lymphoma cells markedly enhanced their sensitivity to lysis by 
$\mathrm{H}_{2} \mathrm{O}_{2}$. Recovery of the tumour cell resistance to $\mathrm{H}_{2} \mathrm{O}_{2}$ after GSH depletion correlated with resynthesis of cellular GSH (Arrick et al., 1982).

Low I-chloro-2,4-dinitrobenzene (CDNB) concentrations caused GSH depletion of the isolated spermatids. This is similar to effects reported for tumour cells, including lymphoma cells which were depleted of GSH in vitro using CDNB (Arrick et al., 1982). CDNB, however, is a much more reactive GST substrate than DEM, and in addition this compound may cause cellular damage through other mechanisms. After raising the GSH level in Chang liver cells, CDNB was found to be more toxic, as concluded from a decreased cloning efficiency, and after lowering the cellular GSH level the toxicity was diminished (Bruggeman et al., 1988). This may indicate that the formed conjugate between CDNB and GSH is more cytotoxic than CDNB itself. In the spermatids, a decrease of the GSH pool at high CDNB concentrations was accompanied by complete loss of cellular ATP, indicative for cell death. Furthermore, diminution of the cellular GSH pool of the spermatids, by DEM treatment, resulted in a lower capacity of the cells to protect themselves against direct cytotoxic effects of CDNB, as indicated by the loss of ATP from the GSH-depleted spermatids at low CDNB concentrations. More experiments will be necessary to elucidate the mechanism of the toxic effects of CDNB and its conjugate. However, it is clear that GSH in spermatids confers protection against CDNB toxicity.

The importance of intracellular free thiol groups in the prevention of cellular damage caused by ionizing radiation has been established in various studies (Meister \& Anderson, 1983). In the present experiments, it was observed that GSH-depleted spermatids were much more sensitive than the control cells to the induction of single-strand DNA breaks by ionizing radiation, as indicated by the higher \% ss-DNA after irradiation with the same gamma-dose. This is in agreement with other studies showing that the radiosensitivity of cells, including CHO cells (Bump et al., 1982; Evans et al., 1984; van der Schans et al., 1986), Hela cells (van der Schans et al., 1986) and human lymphoid cells (Dethmers \& Meister, 1981), is increased when the cells are depleted of GSH.

It is observed that irradiation of GSH-depleted spermatids and control cells under aerobic conditions (air led through the incubation medium) did not show an increased sensitization to radiation damage by the GSH depletion. This confirms the notion that, under aerobic conditions, radiation damage is not dependent on the cellular GSH concentration (van der Schans et al., 1986). The relationship between the concentration of oxygen in the gas atmosphere during irradiation of cultured cells and the effect of depletion of GSH on their radiosensitivity has been studied extensively by van der Schans et al. (1986). These studies showed that GSH depletion of CHO cells resulted in only a small or non-detectable sensitization to DNA damage, when the cells were irradiated under aerobic conditions. Similar results have been obtained by Bump et al. (1982), who observed that GSH depletion of $\mathrm{CHO}$ cells in vitro by diethyl maleate resulted in enhancement of the effect of $\mathrm{X}$-rays on cell killing under hypoxic conditions but not under oxygenated conditions. This is explained by the fact that under aerobic conditions oxygen is present in such a large excess that a lowering of the cellular GSH content does not affect the extent of damage fixation. From the results of the experiments in which spermatids were irradiated under standard incubation conditions, it appears that the oxygen concentration around and within the cells at the time of irradiation must have been very low. This can be concluded because the sensitization of the spermatids to radiation damage by GSH depletion was not detected in air but was pronounced during incubation in 500 p.p.m. $\mathrm{O}_{2}$ in $\mathrm{N}_{2}$.

The repair of the radiation-induced damage in the DNA of the spermatids was not affected by the cellular GSH content. This is in agreement with observations for HeLa and hamster ovary cells, illustrating that GSH depletion by diethyl maleate resulted in a sensitization of induction of DNA damage without an effect on the rate of repair of single-strand DNA breaks (Evans et al., 1984; Vos et al., 1984). The present results show that round spermatids are able to repair single-strand breaks in DNA, and that this repair mechanism is very active in the isolated cells after irradiation. The capacity of the round spermatids for DNA repair, as compared to germ cells from other stages of spermatogenesis is under investigation. 
It can be concluded from the present results that a reduction of the cellular GSH content of isolated spermatids does not directly affect the viability of the cells, unless an oxidative challenge is generated or when toxic compounds are added. Cellular GSH in spermatids is involved in the protection of the cells against oxidative stress and toxic effects of xenobiotics, and is active in the prevention of DNA damage during irradiation. It has not been investigated which exogenous or endogenous factors are inactivated through GSH-supported defence mechanisms in spermatids in situ, in the spermatogenic epithelium. The GSH-mediated protection mechanisms in spermatids may rely on the maintenance of a large intracellular GSH pool. Furthermore, it is very likely that Sertoli cells play an important role in this context, because the Sertoli cells enclose the germ cells, providing support and protection.

This investigation received financial support from the World Health Organization Special Programme of Research, Development and Research Training in Human Reproduction (project 87079), and The Institute of Radiopathology and Radiation Protection, grant 4.7.10, Leiden, The Netherlands.

\section{References}

Arrick, B.A., Nathan, C.F., Griffith, O.W. \& Cohn, Z.A. (1982) Glutathione depletion sensitizes tumor cells to oxidative cytolysis. J. biol. Chem. 257, 1231-1237.

Bruggeman, I.M., Spenkelink, A., Temmink, J.H.M. \& Van Bladeren, P.J. (1988) Differential effects of raising and lowering intracellular glutathione levels on the cytotoxicity of allyl isothiocyanate, tert-butylhydroperoxide and chlorodinitrobenzene. Toxicology in vitro 2, 31-35.

Bump, E.A., Yu, N.Y. \& Brown, J.M. (1982) Radiosensitization of hypoxic tumor cells by depletion of intracellular glutathione. Science, $N Y$ 217, 544-545.

Calvin, H.I. \& Turner, S.I. (1982) High levels of glutathione attained during postnatal development of rat testis. $J$. exp. Zool. 219, 389-393.

Carlberg, I. \& Mannervik, B. (1985) Glutathione reductase. In Methods in Enzymology, vol. 1 13, pp. 484490. Ed. A. Meister. Academic Press, London.

Den Boer, P.J. \& Grootegoed, J.A. (1988) Mechanism of action of $(-)$ gossypol on ATP production in isolated hamster spermatids. J. Reprod. Fert. 83, 693-700.

Den Boer, P.J., Verkerk, A. \& Grootegoed, J.A. (1988) Effect of xenobiotics on glutathione and ATP levels in isolated round spermatids from rats. In The Molecular and Cellular Endocrinology of the Testis, pp. 241-246. Eds B. A. Cooke \& R. M. Sharpe. Raven Press, New York.

Den Boer, P.J., Mackenbach, P. \& Grootegoed, J.A. (1989) Glutathione metabolism in cultured Sertoli cells and spermatogenic cells from hamsters. $J$. Reprod. Fert. 87, 391-400.

Dethmers, J.K. \& Meister, A. (1981) Glutathione export by human lymphoid cells: depletion of glutathione by inhibition of its synthesis decreases export and increases sensitivity to irradiation. Proc. natn. Acad. Sci. USA 78, 7492-7496.

Evans, J.W., Taylor, Y.C. \& Brown, J.M. (1984) The role of glutathione and DNA strand break repair in determining the shoulder of the radiation survival curve. Br. J. Cancer 49, Suppl. VI, 49--53.
Greenstock, C.L. \& Whitehouse, R.P. (1984) Base damage in irradiated DNA and the effect of oxygen. In Oxygen Radicals in Chemistry and Biology, pp. 619 628. Eds W. Bors, M. Saran, M. \& D. Tait. de Gruyter, Berlin.

Griffith, O.W. \& Meister, A. (1979) Potent and specific inhibition of glutathione synthesis by buthionine sulfoximine (S-n-butyl homocysteine sulfoximine). $J$. biol. Chem. 254, 7558-7560.

Grootegoed, J.A., Jansen, R. \& van der Molen, H.J. (1984) The role of glucose, pyruvate and lactate in ATP production by rat spermatocytes and spermatids. Biochim. Biophys. Acta 767, 248-256.

Grootegoed, J.A., Jansen, R. \& van der Molen, H.J. (1985) Intercellular pathway of leucine catabolism in rat spermatogenic epithelium. Biochem. J. 226, 889-892.

Grosshans, K. \& Calvin, H.I. (1985) Estimation of glutathione in purified populations of mouse testis germ cells. Biol. Reprod. 33, 1197-1205.

Habig, W.H., Pabst, M.J. \& Jakoby, W.B. (1974) Glutathione S-transferases. J. biol. Chem. 249, 7130-7139.

Hissin, P.J. \& Hilf, R. (1976) A fluorometric method for determination of oxidized and reduced glutathione in tissues. Analyt. Biochem. 74, 214-226.

Högberg, J. \& Kristoferson, A. (1977) A correlation between glutathione levels and cellular damage in isolated hepatocytes. Eur. J. Biochem. 74, 77-82.

Jensen, G.L. \& Meister, A. (1983) Radioprotection of human lymphoid cells by exogenously supplied glutathione is mediated by $\gamma$-glutamyl transpeptidase. Proc. natn. Acad. Sci. USA 80, 4714-4717.

Ketterer, B. (1986) Detoxication reactions of glutathione and glutathione transferases. Xenobiotica 16, 957-973.

Meister, A. \& Anderson, M.E. (1983) Glutathione. Ann. Rev. Biochem. 52, $711-760$.

Miccadei, S., Kyle, M.E., Gilfor, D. \& Farber, J.L. (1988) Toxic consequence of the abrupt depletion of glutathione in cultured rat hepatocytes. Archs Biochem. Biophys. 265, 311-320. 
Plummer, J.L., Smith, B.R., Sies, H. \& Bend, J.R. (1981) Chemical depletion of glutathione in vivo. In Methods in Enzymology, vol. 77, pp. 50-59. Ed. W. B. Jakoby. Academic Press, London.

Reed, D.J. \& Fariss, M.W. (1984) Glutathione depletion and susceptibility. Pharmacol. Rev. 36, 25S-33S.

Starke, P.E. \& Farber, J.L. (1985) Endogenous defenses against the cytotoxicity of hydrogen peroxide in cultured rat hepatocytes. J. biol. Chem. 260, 86-92.

van der Schans, G.P., Vos, O., Roos-Verheij, W.S.D. \& Lohman, P.H.M. (1986) The influence of oxygen on the induction of radiation damage in DNA in mammalian cells and after sensitization by intracellular glutathione depletion. Int. J. Radiat. Biol. 50, 453-465.

van der Schans, G.P., van Loon, A.A.W.M., Groenendijk, R.H. \& Baan, R.A. (1989) Detection of DNA damage in cells exposed to ionizing radiation by use of antisingle-stranded-DNA monoclonal antibody. Int. $J$. radiat. Biol. 55, 747-760.

Vos, O., van der Schans, G.P. \& Roos-Verheij, W.S.D. (1984) Effects of BSO and DEM on thiol-level and radiosensitivity in Hela cells. Int. J. Radiation Oncology Biol. Phys. 10, 1249-1253.

Received 5 May 1989 